\title{
A 15-year study of the role of Aeromonas spp. in gastro- enteritis in hospitalised children
}

\author{
I. GLUSKIN, D. BATASH*, D. SHOSEYOV, A. MOR*, R. KAZAK, E. AZIZI* and I. BOLDUR $\dagger$
}

Departments of Microbiology and * Pediatrics, Assaf Harofeh Medical Center, affiliated to Sackler Faculty of Medicine, Tel-Aviv University, Israel

\begin{abstract}
Summary. During a 15-year period, 146 strains of Aeromonas spp. were isolated from 32810 faecal specimens from 13820 hospitalised patients up to 13 years of age. These isolates constituted $4 \%$ of all the pathogenic bacterial strains cultured. For the years 1978-1988, the files of children with gastro-enteritis revealed 81 whose faeces yielded Aeromonas spp. Most of them $(94 \%)$ were $<3$ years of age, $78 \%<1$ year old. The peak incidence was at $2-6$ months, involving severe morbidity including dehydration and vomiting with acidaemia and azotaemia; the mean duration of illness and length of hospitalisation at this age were longer than at other ages. Bloody diarrhoea was found in $7 \%$ of the children. Almost all the strains of Aeromonas were resistant to ampicillin. We conclude that Aeromonas spp. are of aetiological significance in gastro-enteritis in small children; culture for this pathogen should be routine in the bacteriological examination of faeces.
\end{abstract}

\section{Introduction}

Aeromonas spp. are ubiquitous in soil and untreated water, causing diseases of fish and amphibians. ${ }^{1}$ These facultatively anaerobic, rod-shaped bacteria in the family Vibrionaceae are considered today as potential enteric human pathogens around the world. ${ }^{2-4}$ They were considered by some authors as opportunist pathogens in immunocompromised patients, ${ }^{3,5,6}$ but today they are recognised as causes of a spectrum of gastrointestinal diseases from self-limiting diarrhoea to acute, persistent dysentery. ${ }^{3,7-10}$ They have been isolated from children with acute diarrhoea and from adults with traveller's diarrhoea. ${ }^{11,12}$ Enterotoxins, cytotoxins and haemolysins were described as possible virulence factors of aeromonas ${ }^{3,13}$ although their role in pathogenesis is not clear. Drinking of untreated water is the most probable manner of exposure to aeromonas. ${ }^{14}$

The present retrospective study of aeromonas infections was undertaken to investigate the bacterial species involved, their sensitivity to antibiotics, the seasonal distribution of the disease, the age and sex incidence, and the range of patients' symptoms.

\section{Materials and methods}

\section{Patients}

During the 15 years, 1974-1988, faecal specimens

Received 6 Aug. 1991 ; revised version accepted 24 Feb. 1992.

$\dagger$ Correspondence should be sent to Dr I. Boldur, Department of Microbiology, Assaf Harofeh Medical Center, Zerifin 70300, Israel. from 13820 hospitalised children with acute gastroenteritis were cultured. The patients, up to 13 years of age, had been admitted with diarrhoea often associated with dehydration, weight loss, vomiting or acidosis. To evaluate the significance of aeromonas as the possible cause of the disease, we analysed only the files of children whose faecal specimens yielded this organism as the sole pathogen.

Statistical analysis of data was performed by the $\chi^{2}$ method.

\section{Bacterial culture and identification}

A faecal specimen was collected from each patient immediately after admission, before treatment; sometimes additional specimens were taken. Undiluted samples were inoculated routinely on MacConkey and Salmonella-Shigella agar plates for the isolation of enteroinvasive, enteropathogenic and enterotoxigenic Escherichia coli, salmonella and shigella. For each, confirmative agglutination tests were performed.

Since 1974 we also examined for Aeromonas spp. Colonies were screened for oxidase by Kovacs' method, ${ }^{15}$ bacteria from one colony being applied to filter paper moistened with two drops of reagent. Oxidase-positive, shiny colonies were transferred to a tube of Kligler iron agar and to semi-solid urea medium. Motile organisms that produced indole but not urease, and fermented glucose rapidly, but lactose only slowly, were further tested with API 20E (API System GA, La Balme Les Grottes, MontalieuVercieu, France): identification as Aeromonas spp. was confirmed by hydrolysis of arginine and liquefaction of gelatin but absence of ornithine decarboxylase. 


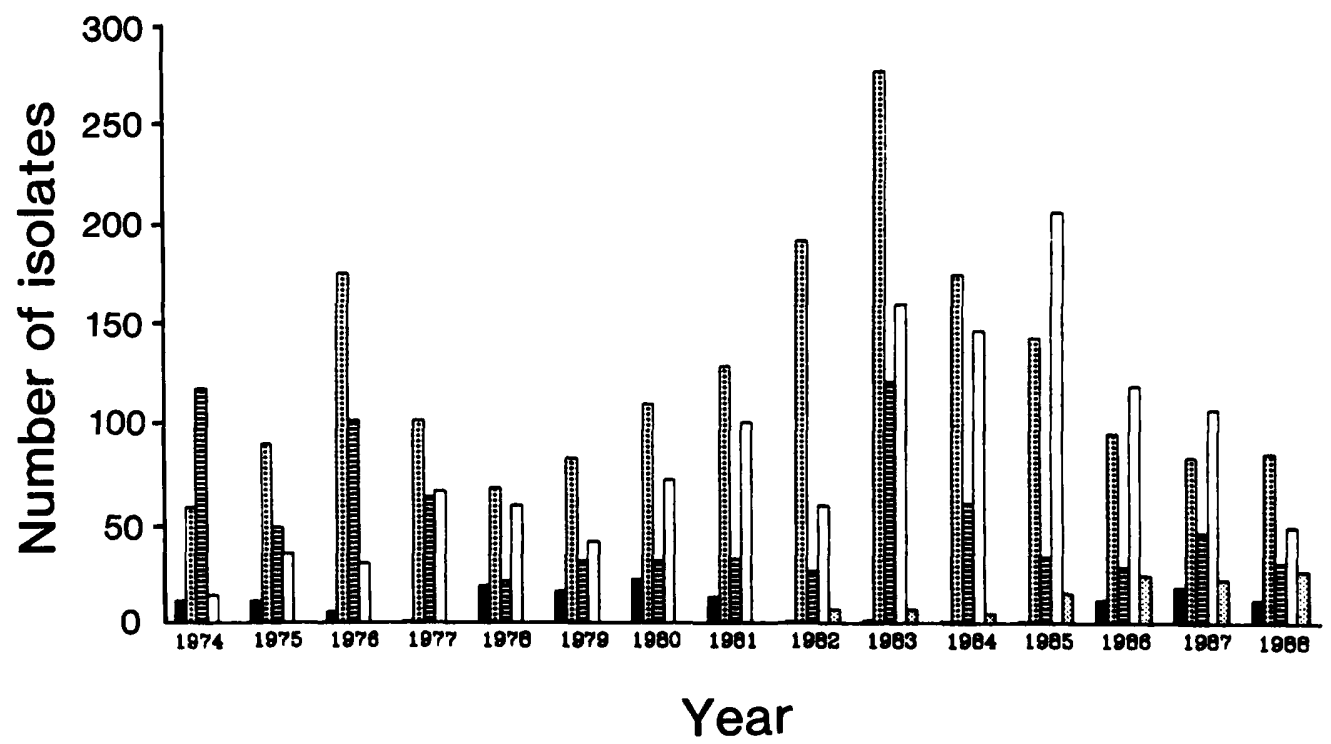

Fig. 1. Yearly distribution of enteric pathogens isolated during a period of 15 years: aeromonas $\square, E$. coli $\square$, salmonella 目, shigella $\square$, campylobacter 图.

Table I. Patients from whom one or more enteric pathogens were isolated during 15 years (1974-1988)

\begin{tabular}{|c|c|c|c|c|}
\hline \multirow{2}{*}{$\begin{array}{l}\text { Pathogen } \\
\text { isolated }\end{array}$} & \multirow{2}{*}{$\begin{array}{l}\text { Number }(\%) \\
\text { of patients } \\
\text { excreting } \\
\text { pathogen } \\
\text { in one or more } \\
\text { specimens } \\
(\mathrm{n}=2567)\end{array}$} & \multicolumn{3}{|c|}{ Number $(\%)$ of specimens that yielded } \\
\hline & & $\begin{array}{l}\text { one or more } \\
\text { pathogens } \\
(n=4045)\end{array}$ & $\begin{array}{c}\text { one } \\
\text { pathogen } \\
(n=3926)\end{array}$ & $\begin{array}{c}\text { more than one } \\
\text { pathogen } \\
(n=119)^{*}\end{array}$ \\
\hline E. coli & $1272(50)$ & $1840(45)$ & 1750 & 116 \\
\hline Shigella & $759(30)$ & $1257(31)$ & 1196 & 68 \\
\hline Salmonella & 496 (19) & 781 (19) & 747 & 42 \\
\hline Aeromonas & $103(4)$ & $146(4)$ & 141 & 5 \\
\hline Campylobacter & $76(4) \dagger$ & $101(4) \dagger$ & 92 & 9 \\
\hline Total isolates & $\ldots$ & $\ldots$ & 3926 & 240 \\
\hline
\end{tabular}

* Number of specimens with two or more pathogens of the same genus or of different genera. $\dagger$ Derived from 1757 patients since the year 1982, whose 2392 specimens yielded one or more pathogens.

Lack of sensitivity to the vibriostatic agent 0129 was also used to differentiate Aeromonas from Vibrio.

Identification of aeromonas to species level was performed by the Central Laboratories of the Ministry of Health, Jerusalem, and was based on production of gas from glucose, of acetoin, $\mathrm{H}_{2} \mathrm{~S}$ and lysine decarboxylase, and on aesculin hydrolysis and fermentation of arabinose and salicin. ${ }^{16}$

Antibiograms were performed by the Kirby-Bauer disk method on Mueller-Hinton agar. ${ }^{17}$ The strains were defined as susceptible, resistant or of intermediate resistance, as recommended by Barry and Thornsberry. ${ }^{18}$

Since 1982, specimens were also examined for campylobacter, on Butzler medium prepared with Columbia agar and containing human blood $6 \%$.

\section{Results}

During the period 1974-1988, 32810 faecal specimens from 13820 children were cultured for enteric pathogens. The yearly distribution of the isolates is shown in fig. 1; 4045 specimens yielded a pathogen; $1840(45 \%)$ contained specific strains of $E$. coli, 1257 (31\%) shigella, $781(19 \%)$ salmonella, and $146(4 \%)$ had Aeromonas spp.; since 1982, 101 (4\%) contained campylobacter. The number of isolates of Aeromonas spp. was highest (22) in 1980, and was lowest during 1977 and 1982-1985 (one or two isolations each year).

The isolates from 4045 specimens containing one or more pathogens are shown in table I. Most yielded only one pathogen; but 119 yielded two or three, giving a total of 240 isolates. Aeromonas spp. were associated with other pathogens in five specimens: with $E$. coli (3), campylobacter (1) and shigella (1). Fig. 2 shows that aeromonas was isolated throughout the year, with a somewhat higher incidence in the summer months.

During the last 11 years of the study (1978-1988), 117 isolates of Aeromonas spp. were obtained as the sole pathogen from the faeces of 81 patients. The charts of these patients were reviewed, and clinical information was analysed and processed on computercompatible data sheets. Of the 81 patients, 54 were 


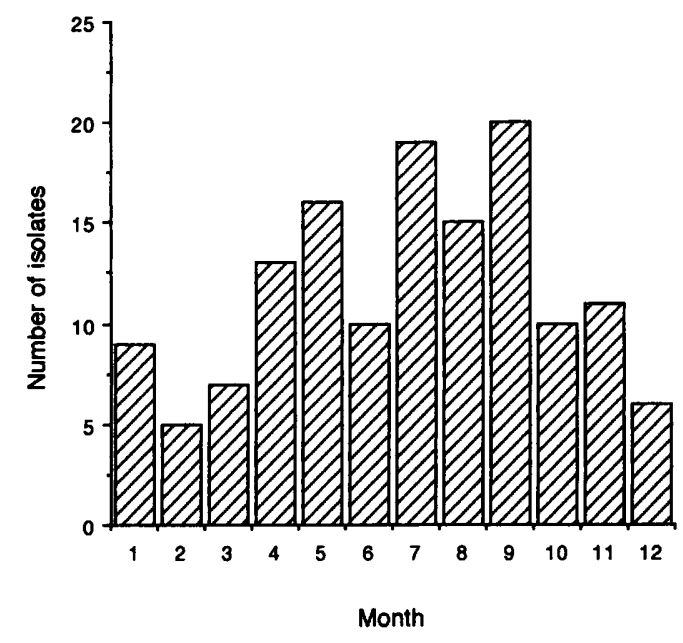

Fig. 2. Seasonal distribution of Aeromonas spp. isolated from samples of faeces during a 15 -year period.

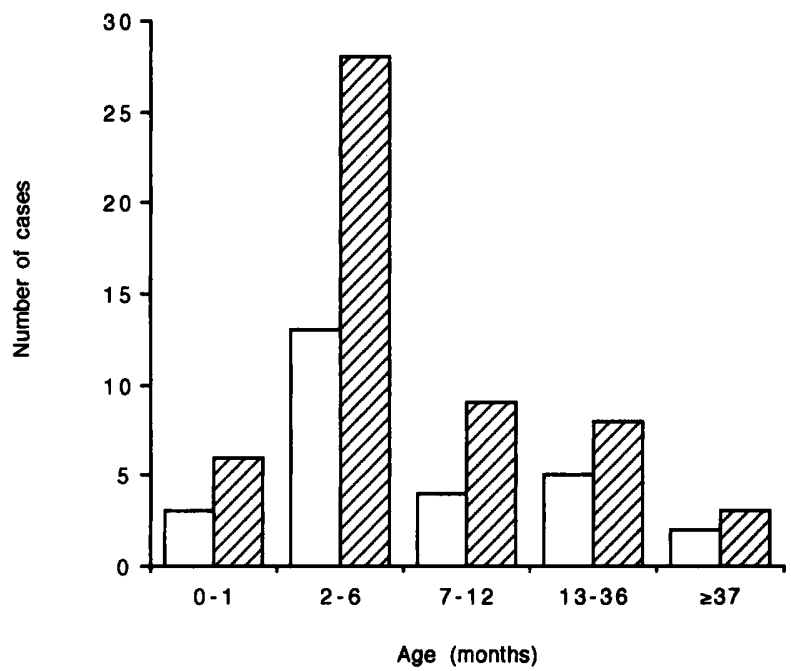

Fig. 3. Age and sex of cases of enteritis caused by Aeromonas spp. girls, $\square$, boys $\square$.

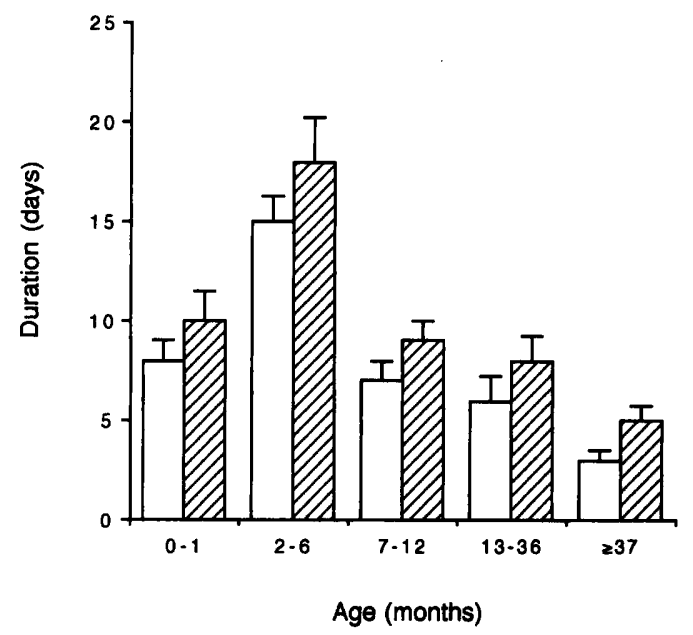

Fig. 4. Mean duration (and SEM) of illness $\square$ and hospitalisation $\square$ in different age groups.

boys and 27 girls; the peak incidence for both was at 2-6 months, an age group in which $52 \%$ of the male and $48 \%$ of the female cases were clustered (fig. 3 ). The mean duration of illness and hospitalisation of this group was significantly longer than for other age groups (fig. 4). The mean duration of illness increased from $12 \cdot 2$ days (0-1 month) to $20 \cdot 1$ days (2-6 months)
Table II. Susceptibility of isolates of Aeromonas spp. to antibiotic and chemotherapeutic agents

\begin{tabular}{l|ccc}
\hline \multirow{2}{*}{$\begin{array}{c}\text { Antibiotic or } \\
\text { chemotherapeutic }\end{array}$} & \multicolumn{3}{|c}{ Number (\%) of strains } \\
\cline { 2 - 4 } $\begin{array}{c}\text { agent (number of } \\
\text { strains tested) }\end{array}$ & susceptible & $\begin{array}{c}\text { of intermediate } \\
\text { resistance }\end{array}$ & resistant \\
\hline Ampicillin (81) & $3(4)$ & $5(6)$ & $73(90)$ \\
Chloramphenicol (81) & $79(98)$ & 0 & $2(2)$ \\
Tetracycline (81) & $73(90)$ & $4(5)$ & $4(5)$ \\
Cefoxitin (41) & $34(83)$ & $1(2)$ & $6(15)$ \\
Cotrimoxazole (79) & $61(77)$ & $3(4)$ & $15(19)$ \\
\hline
\end{tabular}

and then decreased gradually to $5 \cdot 2$ days for children over 3 years old ( $p<0.01$ and $p<0.05$, respectively). The mean duration of hospitalisation was 9.9 days (0-1 month), 15.6 days ( $2-6$ months), and 3.8 days ( $>3$ years old).

The Central Laboratories of the Ministry of Health examined 46 of the Aeromonas isolates: $24(52 \%)$ were identified as $A$. hydrophila, $11(24 \%)$ as $A$. caviae and seven ( $15 \%$ ) as $A$. sobria; four ( $9 \%$ ) were atypical.

Among the symptoms of aeromonas infection, the most frequent was diarrhoea $(91 \%)$. Stools were watery in $39(48 \%)$, mucous in $29(36 \%)$ and bloody in six $(7 \%)$ of the patients. Vomiting occurred in 59 $(73 \%) ; 34(42 \%)$ showed signs of dehydration. The average weight-loss of the dehydrated patients was $8 \%$ of the last known previous weight; 18 of the dehydrated children showed metabolic acidosis in venous blood samples $(\mathrm{pH}$ decreased to $<7.3$ and $\mathrm{HCO}_{3}{ }^{-}<15 \mathrm{meq} / \mathrm{L}$ ).

The susceptibility of Aeromonas spp. to antibiotic and chemotherapeutic agents is shown in table II: most strains were resistant to ampicillin but susceptible to the other agents tested. We did not find significant differences in antibiotic sensitivity pattern among the three species $(p>0.5)$.

\section{Discussion}

Previous studies have shown that aeromonas is isolated more frequently from the faeces of patients with diarrhoea ${ }^{7,8}$ than from normal stools. In the only published study from our area, none of 500 specimens from healthy adults yielded aeromonas. ${ }^{10}$ In a preliminary study to the present one, the isolation rate from 461 children without gastro-intestinal symptoms was only $1 \%$ : four isolates from children aged 7-12 months and one from a child over 3 years old (unpublished observations).

The reported prevalence of aeromonas in human faeces varies widely, from $0.1 \%$ to $27 \%$, depending on the climate, the quality of drinking water, the hygiene of the population, and the methods of bacterial

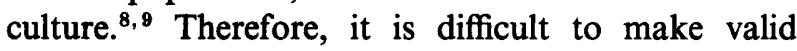
comparisons of isolation rates. In the USA, an association was shown between the drinking of untreated water and the isolation of aeromonas from cases of diarrhoea. ${ }^{14} \mathrm{~A}$ study in Israel found large 
numbers of the organism in the water of an uncovered reservoir $;{ }^{19}$ but usually, drinking water is not screened for aeromonas. The water for the patients in the present study came from the national system and from local reservoirs. The quality of water in Israel is generally acceptable, and the population is notified if it becomes unsatisfactory.

In our experience, the culture methods did not present difficulties: the organism grew well on the media used routinely. The oxidase test provided an easy and efficient screening method for colonies resembling $E$. coli, though the occurrence of "oxidasevariable" strains has been reported. ${ }^{20}$ Treatment with ampicillin or cotrimoxazole before hospitalisation is unusual, so it is doubtful if this influenced the isolation rates.

In Australia, ${ }^{12} 127$ of 975 children with diarrhoea yielded Aeromonas spp., compared with only 20 matched controls. After peptone water enrichment of unselected routine faecal specimens from 1004 patients in an English hospital, aeromonas was found in $4 \%$, but it was possibly associated with gastrointestinal symptoms in only half of these; the isolation rate was higher in children : $8 \%$ in children under 1 year, $7 \%$ in those aged 1-13 years. ${ }^{21}$ Moyer ${ }^{22}$ found an isolation rate of $7 \%$ among patients with diarrhoea in Iowa, USA; and it was as high as $30 \%$ in children under 3

\section{References}

1. Buchanan RL, Palumbo SA. Aeromonas hydrophila and Aeromonas sobriae as potential food poisoning species; a review. J Food Safety 1985; 7: 15-29.

2. Nazer H, Price EH, Hunt GH, Walker-Smith JA. Clinical associations of Aeromonas spp. in fecal specimens from children. Clin Pediatr 1986; 25: 516-519.

3. Holmberg SD, Farmer JJ. Aeromonas hydrophila and Plesiomonas shigelloides as causes of intestinal infections. Rev Infect Dis 1984; 6: 633-639.

4. San Joaquin VH, Pickett DA. Aeromonas-associated gastroenteritis in children. Pediatr Infect Dis $J$ 1988; 7: 53-57.

5. Schoch PE, Cunha BA. Aeromonas. Infect Control 1984; 5: 542-544.

6. Washington JA. Aeromonas hydrophila in clinical bacteriologic specimens. Ann Intern Med 1972; 76: 611-614.

7. George WL, Nakata MM, Thompson J, White ML. Aeromonasrelated diarrhea in adults. Arch Intern Med 1985; 145: 2207-2211.

8. Gracey M, Burke V, Robinson J. Aeromonas-associated gastroenteritis. Lancet 1982; 2: 1304-1306.

9. Agger WA, McCormick JD, Gurwith MJ. Clinical and microbiological features of Aeromonas hydrophila-associated diarrhea. J Clin Microbiol 1985; 21 : 909-913.

10. Golik A, Modai D, Gluskin I, Schechter I, Cohen N, Eschchar J. Aeromonas in adult diarrhea: an enteropathogen or an innocent bystander? J Clin Gastroenterol 1990; 12: $148-152$.

11. Echeverria P, Blocklow NR, Sanford IB, Cakor GG. Traveler's diarrhea among American Peace Corps volunteers in rural Thailand. J Infect Dis 1981; 143: 767-771.

12. Burke V, Gracey M, Robinson J, Peck D, Beaman J, Bundell C. The microbiology of childhood gastroenteritis: years and in middle-aged adults. Our isolation rate of only $4 \%$ may have been influenced by the severity of enteric disease that led to hospitalisation.

Studies in different countries have shown a peak isolation rate of Aeromonas spp. in the summer and autumn. ${ }^{12,21}$ In the present study, and in a previous study in adults, ${ }^{10}$ more cases of aeromonas gastroenteritis were found during the spring, summer and autumn, but the differences were not statistically significant; this could be due to the relatively slight differences in weather between our seasons.

Few of our patients were in the first month of life, probably due to lack of exposure and to the protective effect of maternal antibodies. Children aged 1-6 months showed a peak incidence, and also the highest duration of illness and of hospitalisation. Aeromonas diarrhoea was frequently associated with vomiting, dehydration, weight-loss and acidosis. No correlation was found between the species of Aeromonas and the clinical features - bloody, watery or mucous diarrhoea, or dehydration ( $p>0.5)$. It is noteworthy that $42 \%$ of the children in our study were dehydrated and $7 \%$ had bloody diarrhoea. We conclude that Aeromonas spp. are important causes of intestinal infection especially in small children.

We thank Dr H. Schechter for the species identification of strains of aeromonas, and Mrs S. Zarini for typing the manuscript.
Aeromonas species and other Infective Agents. J Infect Dis 1983; 148: 68-74.

13. Goodwin CS, Harper WES, Stewart JK, Gracey M, Burke V, Robinson J. Enterotoxigenic Aeromonas hydrophila and diarrhea in adults. Med J Austr 1983; 1: 25-26.

14. Holmberg SD, Schell WL, Fanning GR et al. Aeromonas intestinal infections in the United States. Ann Intern Med 1986 ; 105 : 683-689.

15. Von Graevenitz A, Mensch AH. The genus Aeromonas in human bacteriology; report of 30 cases and review of the literature. $N$ Engl J Med 1968; 278: 245-249.

16. Janda JM, Reitano M, Bottone EJ. Biotyping of Aeromonas isolates as a correlate to delineating a species-associated disease spectrum. J Clin Microbiol 1984; 19: 44-47.

17. Bauer AW, Kirby WM, Sherris JC, Turck M. Antibiotic susceptibility testing by a standardized single disk method. Am J Clin Pathol 1966; 45: 493-496.

18. Barry LA, Thornsberry C. Susceptibility tests: diffusion test procedure. In: Lenette HE et al. (eds) Manual of clinical microbiology, Washington D.C., American Society for Microbiology. 1985.

19. Schechter H, Schechter I. The Aeromonas group as interference in the standard coliform MPN test of fresh water. Isr J Med Sci $1974 ;$ 13: 646-647.

20. Overman TL, D'Amato RF, Tomfohrde KM. Incidence of "oxidase-variable" strains of Aeromonas hydrophila. J Clin Microbiol 1979; 9: 244-247.

21. Millership SE, Curnow SR, Chattopadhyay B. Faecal carriage rate of Aeromonas hydrophila. J Clin Pathol 1983; 36: 920-923.

22. Moyer NP. Clinical significance of Aeromonas species isolated from patients with diarrhea. J Clin Microbiol 1987; 25: 2044-2048. 